\title{
Sharing of retracted COVID-19 articles: an altmetric study
}

\author{
Amrollah Shamsi; Brady Daniel Lund; Shohreh SeyyedHosseini \\ See end of article for authors' affiliations.
}

\begin{abstract}
Objective: This study examines the extent to which retracted articles pertaining to COVID-19 have been shared via social and mass media based on altmetric scores.

Methods: Seventy-one retracted articles related to COVID-19 were identified from relevant databases, of which thirty-nine had an Altmetric Attention Score obtained using the Altmetrics Bookmarklet. Data extracted from the articles include overall attention score and demographics of sharers (e.g., geographic location, professional affiliation).
\end{abstract}

Results: Retracted articles related to COVID-19 were shared tens of thousands of times to an audience of potentially hundreds of millions of readers and followers. Twitter was the largest medium for sharing these articles, and the United States was the country with the most sharers. While general members of the public were the largest proportion of sharers, researchers and professionals were not immune to sharing these articles on social media and on websites, blogs, or news media.

Conclusions: These findings have potential implications for better understanding the spread of misleading or false information perpetuated in retracted scholarly publications. They emphasize the importance of quality peer review and research ethics among journals and responsibility among individuals who wish to share research findings.

Keywords: COVID-19; retractions; altmetrics; articles; social media

\section{INTRODUCTION}

The COVID-19 pandemic remains a serious health concern worldwide despite vaccine development. This emergency situation resulted in a vast body of literature related to the pandemic. Since February 20, 2020, 137 scientific papers have been published per day, on average, on the topic of COVID-19 [1]. Universal hurry related to the production of scholarship on the pandemic has increased the speed of scientific productivity and researchers' inaccuracy and has accelerated the review process, inviting a greater likelihood of research misbehavior [2]. Thus, the rapid growth of COVID-19 literature has led to a major, unfortunate outcome; the ratio of retracted articles is much greater, compared historically, than that for other research topics [1].

Scientific misconduct plays a prominent role in the retraction of articles from the biomedical literature [3]. Scientific misconduct is "fabrication, falsification or plagiarism in proposing, performing or reviewing research or in reporting research results" according to the
US Office of Research Integrity [4]. Serious deficiencies in the quality of empirical findings and conclusions drawn by these articles [5] could undermine scholars' trust in their reported results [2]. Furthermore, retractions can have negative consequences for authors [6] and lead to irrecoverable injuries for patients if improper methodologies or findings from these retracted studies are employed in clinical settings [7].

During the COVID-19 pandemic, with most individuals practicing social distancing and isolating to protect themselves, online sources were increasingly consulted in order to find and share information $[8,9]$. Social platforms, including social media and research sharing websites (e.g., Mendeley), have the tremendous capability to increase the visibility of and disseminate coronavirus-related research $[10,11]$. However, invalid or distorted information shared on social platforms can have serious adverse effects on readers as well as medical practitioners, who may use information in retracted articles to inform clinical decision-making [12, 13, 14]. 
Altmetrics are alternative metrics to traditional bibliometric indicators (e.g., citations) that document the impact or dissemination of scholarly works on platforms like social media, online news sites, blogs, and researchsharing sites. Altmetrics are a rapid indicator of the impact of an article within public discourse, as the article can be "cited" on platforms like Twitter on the same day it is published [15]. Recent studies show that retracted articles published in reputable journals, like Lancet or New England Journal of Medicine, can attain "astronomical" altmetrics scores through being spread on social platforms, especially Twitter [16]. Given the importance of social media to the dissemination of COVID-19 information, some altmetrics studies have already been performed, but they lack a specific and extensive focus on retracted articles [17-21].

Given the potentially dangerous impact of retracted COVID-19 articles on disease prevention and intervention and the unique role of social media and other articlesharing platforms in this era, this study aims to expand on a prior study by Cortegiani et al. [13] to provide insight into the current state of retracted COVID-19 articles through an altmetrics lens. While Cortegiani et al.'s study focused on social media coverage of retracted articles in general, we focus on altmetrics for retracted COVID-19 articles specifically. Our central research question is to what extent have retracted COVID-19 articles been shared online prior to retraction as indicated by altmetrics? In particular, we sought to determine how many times these articles were shared, who was responsible for sharing them, and the potential size of the audience.

\section{METHODS}

Data for this study were retrieved in early March 2021 from three sources: the Retraction Watch Database (https:// retractiondatabase.org/), Scopus, and PubMed. Using an approach adapted from Soltani and Patini's 2020 study of retracted COVID-19 articles, the following search terms were used to identify retracted manuscripts originally published between January 1, 2020, and March 1, 2021: "COVID-19," “coronavirus disease 2019," "coronavirus 2019," "coronavirus 2020," "SARS-COV-2," and "2019-nCOV." Only articles that were retracted based on a factual or methodological error on the part of the author were included; articles that were retracted only due to a publisher error were not included. Note, however, that over time some articles may be revised and republished following their retraction, which may mean that some articles classified as retracted in this study may have been republished at the time of this writing.

Seventy-four retracted articles were initially retrieved using this strategy. However, three of these articles lacked a digital object identifier (DOI) or PubMed ID, which made it impossible to collect altmetric data, and were thus excluded from the study. Of the remaining seventy-one articles, thirty-nine had an Altmetric Attention Score, whereas thirty-two were not shared before retraction. These thirty-nine articles constituted the final population for this study (Appendix A).

Altmetric Attention Score for each article was obtained from the Altmetrics Bookmarklet, available at https:/ / www.altmetric.com, on March 1, 2021. This application aggregates sharing data for all social platforms, including how frequently an article has been shared on each platform and potential audience size (i.e., number of subscribers to sharers' accounts). These data are aggregated from a wide variety of platforms, including public policy documents (particularly relevant during the COVID-19 pandemic), online publication-sharing platforms (e.g., Mendeley, ResearchGate), Wikipedia, blogs, social media sites (e.g., Facebook, Twitter, Reddit, Weibo), and video-sharing platforms (e.g., YouTube).

As Altmetric Attention Scores are updated each time an article is shared, scores collected for analysis are reflective only of a particular point in time; however, collection of altmetrics data for this study was performed after all articles had been retracted. Among the 39 articles examined, a mean of 203 days had passed from the date of retraction to the date of data collection (median $=227$ days), with a range of 10 to 378 days. The correlation between the time since retraction and Altmetric Attention Score was 0.19 , indicating that articles retracted further in the past did not necessarily accrue higher scores.

Using the Altmetrics Bookmarklet, an altmetrics page can be accessed for each article included in the Altmetrics database, which includes the overall Altmetric Attention Score and a breakdown of its contributing sources. By clicking on a section entitled "click for more details," a more detailed breakdown is shown, including profile information for individuals who shared an article on social media or saved the article on Mendeley. This allows the reader or researcher to have a better understanding of not only how much an article has been shared, saved, or discussed but also who has done the sharing, saving, or discussing. For the disciplinary affiliation (e.g., medical sciences, natural sciences, social sciences) of Mendeley readers, information from user profiles was used to thematically align readers with the most appropriate Mendeley discipline classification. In some cases, this process is nearly automatic, based on data provided in the Altmetrics Bookmarklet, but in other cases it requires careful inspection of a profile and agreement among the researchers as to the most appropriate affiliation. 
Figure 1 Number of articles shared and total shares on each platform

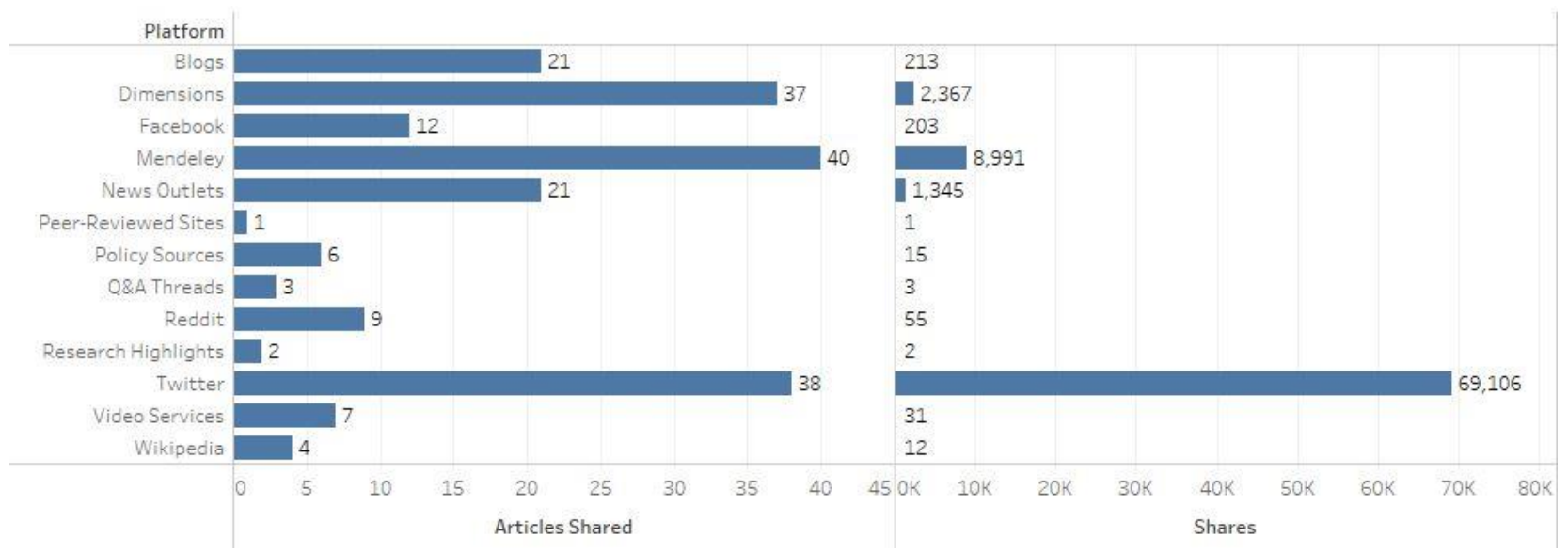

Data were transferred from the Altmetrics Bookmarklet to Microsoft Excel for further analysis. While a single member of the research team was responsible for initially collecting the data, all data were checked by a second team member using the Bookmarklet and Excel spreadsheet to ensure accuracy in transcribing the scores.

\section{RESULTS}

\section{Platforms contributing to Altmetric Attention Scores}

The number of articles shared or saved on each platform and the total number of shares for each are shown in Figure 1. The most prominent platforms were Mendeley, which registers when a user saves an article to their account, and Twitter, which registers when a user tweets about an article. The fact that these platforms are responsible for the most shares is logical, given that the effort to share an article on them is as simple as saving an article or tweeting or retweeting about it. Conversely, registering a "share" on Wikipedia or in a policy source requires considerable effort, as the author must actually write or edit an article or policy that cites one of the retracted articles.

\section{Demographics of sharers of retracted articles}

The geographic distribution of Twitter sharers based on information in their account profiles and geotagging of their tweets provides an idea of which countries were most responsible for sharing these retracted articles. As shown in Table 1, the largest percentage of tweets originated in the United States, United Kingdom, France, and Japan.

Table 2 displays the demographic breakdown of individuals who tweeted about the retracted articles. Members of the general public were the most common Twitter users, rather than scientists, doctors, or writers. However, substantial portions of Twitter users were members of one of these three professional groups, who have important roles in vetting the quality of and disseminating scientific findings to the public.

Table 3 shows the backgrounds of readers of the retracted articles in Mendeley. Fourteen percent of all Mendeley readers were professional researchers. Students, though, represented the largest group of identified readers, with bachelor's, master's, and $\mathrm{PhD} /$ doctoral student readers representing a combined $31 \%$.

\section{Discipline of readers of retracted articles}

Table 4 displays the disciplinary affiliations of readers who saved the retracted articles on Mendeley. Unsurprisingly, a large portion of readers whose affiliation could be identified were associated with a biomedical discipline ( $82 \%)$. Comparatively, social sciences disciplines had very little representation among Mendeley readers $(\sim 3 \%)$.

Table 1 Number of tweets about retracted articles by country

\begin{tabular}{lll}
\hline Country & $\begin{array}{l}\text { Number of } \\
\text { tweets }\end{array}$ & $\begin{array}{l}\text { Percentage } \\
\text { of tweets }\end{array}$ \\
\hline United States & 8,434 & $16.00 \%$ \\
\hline United Kingdom & 4,382 & $8.31 \%$ \\
\hline France & 4,007 & $7.60 \%$ \\
\hline Japan & 2,147 & $4.07 \%$ \\
\hline Brazil & 1,443 & $2.74 \%$ \\
\hline Canada & 1,163 & $2.21 \%$ \\
\hline Spain & 882 & $1.67 \%$ \\
\hline Thailand & 736 & $1.40 \%$ \\
\hline
\end{tabular}


Table 1 Number of tweets about retracted articles by country (continued)

\begin{tabular}{|c|c|c|}
\hline Mexico & 400 & $0.76 \%$ \\
\hline Germany & 322 & $0.61 \%$ \\
\hline El Salvador & 260 & $0.49 \%$ \\
\hline Australia & 241 & $0.46 \%$ \\
\hline Italy & 139 & $0.26 \%$ \\
\hline Ukraine & 89 & $0.17 \%$ \\
\hline Colombia & 86 & $0.16 \%$ \\
\hline Korea, Republic of & 85 & $0.16 \%$ \\
\hline Hong Kong & 85 & $0.16 \%$ \\
\hline China & 84 & $0.16 \%$ \\
\hline Netherlands & 80 & $0.15 \%$ \\
\hline India & 73 & $0.14 \%$ \\
\hline Poland & 41 & $0.11 \%$ \\
\hline Chile & 18 & $0.03 \%$ \\
\hline $\begin{array}{l}\text { Korea, Democratic People's } \\
\text { Republic of }\end{array}$ & 11 & $0.02 \%$ \\
\hline Switzerland & 7 & $0.01 \%$ \\
\hline Romania & 4 & $0.01 \%$ \\
\hline Solomon Islands & 4 & $0.01 \%$ \\
\hline Nepal & 3 & $0.01 \%$ \\
\hline Singapore & 3 & $0.01 \%$ \\
\hline Ecuador & 3 & $0.01 \%$ \\
\hline Ireland & 3 & $0.01 \%$ \\
\hline Turkey & 2 & $0.01 \%$ \\
\hline Argentina & 2 & $0.01 \%$ \\
\hline South Africa & 2 & $0.01 \%$ \\
\hline Costa Rica & 2 & $0.01 \%$ \\
\hline Kenya & 2 & $0.01 \%$ \\
\hline Sweden & 1 & $0.01 \%$ \\
\hline New Zealand & 1 & $0.01 \%$ \\
\hline Bermuda & 1 & $0.01 \%$ \\
\hline Comoros & 1 & $0.01 \%$ \\
\hline Indonesia & 1 & $0.01 \%$ \\
\hline Curaçao & 1 & $0.01 \%$ \\
\hline Sierra Leon & 1 & $0.01 \%$ \\
\hline Iceland & 1 & $0.01 \%$ \\
\hline Saudi Arabia & 1 & $0.01 \%$ \\
\hline Unknown & 27,456 & $51.94 \%$ \\
\hline
\end{tabular}

Table 2 Demographic breakdown of Twitter users

\begin{tabular}{llll}
\hline Rank & Twitter users & $\begin{array}{l}\text { Number of } \\
\text { tweets }\end{array}$ & $\begin{array}{l}\text { Percentage of } \\
\text { tweets }\end{array}$ \\
\hline 1 & Members of the public & 64,810 & $94.2 \%$ \\
\hline 2 & Scientists & 2,284 & $3.3 \%$ \\
\hline 3 & $\begin{array}{l}\text { Practitioners (doctors, } \\
\text { other health care } \\
\text { professionals) }\end{array}$ & 1,033 & $1.5 \%$ \\
\hline 4 & $\begin{array}{l}\text { Science communicators } \\
\text { (journalists, bloggers, } \\
\text { editors) }\end{array}$ & 608 & $0.9 \%$ \\
\hline
\end{tabular}

Table 3 Demographic breakdown of Mendeley readers

\begin{tabular}{llcl}
\hline Rank & $\begin{array}{l}\text { Readers by } \\
\text { professional status }\end{array}$ & $\begin{array}{l}\text { Number of } \\
\text { readers }\end{array}$ & $\begin{array}{l}\text { Percentage } \\
\text { of readers }\end{array}$ \\
\hline 1 & Researcher & 1,247 & $14 \%$ \\
\hline 2 & Bachelor's student & 1,002 & $11.3 \%$ \\
\hline 3 & Master's student & 926 & $10.4 \%$ \\
\hline 4 & PhD student & 683 & $7.7 \%$ \\
\hline 5 & Doctoral student & 117 & $1.3 \%$ \\
\hline 6 & Lecturer & 31 & $0.4 \%$ \\
\hline 7 & Postgraduate student & 29 & $0.3 \%$ \\
\hline 8 & Librarian & 12 & $0.1 \%$ \\
\hline 9 & Professor & 10 & $0.1 \%$ \\
\hline 10 & Associate professor & 10 & $0.1 \%$ \\
\hline 12 & Unknown/unspecified/other & 4,823 & $54 \%$ \\
\hline
\end{tabular}

Table 4 Discipline of Mendeley readers

\begin{tabular}{llll}
\hline Rank & Discipline & $\begin{array}{l}\text { Number } \\
\text { of } \\
\text { readers }\end{array}$ & Percentage \\
\hline 1 & Medicine \& dentistry & 2,517 & $28.8 \%$ \\
\hline 2 & $\begin{array}{l}\text { Biochemistry, genetics \& } \\
\text { molecular biology }\end{array}$ & 503 & $5.8 \%$ \\
\hline 3 & Nursing \& health professions & 415 & $4.8 \%$ \\
\hline 4 & $\begin{array}{l}\text { Agricultural \& biological } \\
\text { sciences }\end{array}$ & 341 & $3.9 \%$ \\
\hline 5 & $\begin{array}{l}\text { Pharmacology, toxicology \& } \\
\text { pharmaceutical science }\end{array}$ & 205 & $2.4 \%$ \\
\hline 6 & Immunology \& microbiology & 180 & $2.1 \%$ \\
\hline 7 & Engineering & 157 & $1.8 \%$ \\
\hline
\end{tabular}


Table 4 Discipline of Mendeley readers (continued)

\begin{tabular}{llll}
\hline 8 & Computer science & 140 & $1.6 \%$ \\
\hline 9 & Psychology & 66 & $0.8 \%$ \\
\hline 10 & Social sciences & 47 & $0.5 \%$ \\
\hline 12 & Environmental science & 47 & $0.5 \%$ \\
\hline 13 & Neurosciences & 16 & $0.2 \%$ \\
\hline 14 & $\begin{array}{l}\text { Burth \& planetary sciences } \\
\text { accounting }\end{array}$ & 9 & $0.1 \%$ \\
\hline 15 & Chemistry & 7 & $0.1 \%$ \\
\hline 16 & Philosophy & 3 & $0.03 \%$ \\
\hline 17 & $\begin{array}{l}\text { Economics, econometrics \& } \\
\text { finance }\end{array}$ & 1 & $0.01 \%$ \\
\hline 18 & Arts \& humanities & 1 & $0.01 \%$ \\
\hline 19 & Material Sciences & 1 & $0.01 \%$ \\
\hline 20 & Chemical engineering & 1 & $0.01 \%$ \\
\hline 21 & Unknown/unspecified/other & 4,076 & $46.5 \%$ \\
\hline
\end{tabular}

\section{DISCUSSION}

This study indicates that retracted COVID-19 articles have been widely disseminated and shared online as evidenced by Altmetric Attention Scores. Twitter, in particular, is the platform with the widest sharing of retracted articles, with nearly 70,000 tweets reaching an audience of potentially over 50 million followers, which could cause substantive damage if the retracted articles disseminate false or misleading information. Furthermore, news outlets, which tend to have a significant audience and reach, shared the articles or information over 1,000 times, illustrating the breadth with which misinformation may be spread.

Members of the general public (i.e., nonscientists/experts) appeared to be the most common sharers of retracted articles, although most sharers on Mendeley and other scholarly platforms were professionals or scholars. Among these professionals, those in biomedical fields appeared to be most likely to share. This is potentially problematic, as medical professionals often use recent scholarly research to inform clinical decision-making, such as diagnoses, treatment, and other medical advice offered to patients. Retracted medical papers could lead to deleterious health and medical decisions, as seen in the wake of studies in the early twenty-first century that linked vaccines with autism [21].

Libraries, particularly those that specialize in medical sciences or work frequently with the public, can play an important role in educating about COVID misinformation $[22,23]$. While it may not be possible or reasonable to expect librarians to identify or be aware of all problematic articles that are circulating on the Internet, awareness of the extent to which retracted COVID-19 articles have been circulated could be beneficial when assisting patrons in parsing through emerging literature. Resources like Retraction Watch can be used to inform inquiring members of the public about these articles' statuses.

The main limitation of this study relates to limitations on data availability. Particularly with Mendeley, professional affiliations and research areas were not available for approximately half of researchers. Though it may be possible to match researchers through further searching (e.g., checking university websites), the time required to find this information is prohibitive. Further research could also expand this analysis by examining the context of how these retracted articles are cited in social media and other platforms. For instance, it is possible that some sharers may have shared an article with a note like "great information!" or "I'm not sure about this one," with each conveying a different tone about the article. Additionally, our study's scope was limited to Englishlanguage articles, as we were not able to easily analyze articles published in other languages.

In conclusion, the sharing of retracted articles related to COVID-19 has created a pandemic of its own - one of the rapid spread of incorrect or misleading facts, or infodemic. This study demonstrates the prodigious reach of only thirty-nine retracted COVID-19 articles over a short time frame. The impact of this spread, affecting potentially tens of millions of people, is difficult to comprehend and illustrates the irreparable harm that can be done when rigorous peer review and research ethics are not observed.

\section{DATA AVAILABILITY STATEMENT}

All data associated with this article are available at http://dx.doi.org/10.13140/RG.2.2.36469.70885.

\section{REFERENCES}

1. Yeo-Teh NSL, Tang BL. An alarming retraction rate for scientific publications on coronavirus disease 2019 (COVID19). Account Res. 2021;28(1):47-53.

2. Mansourzadeh MJ, Shamsi A. Concerns about research ethics in COVID-19 publications. Asia Pacific Journal of Public Health. 2020;32(8):503-4.

3. Elango B. Retracted articles in the biomedical literature from Indian authors. Scientometrics. 2021;126(5):3965-81.

4. Office of Research Integrity. Definition of research misconduct [Internet]. US Department of Health and Human Services [cited 7 Mar 2021]. <https://ori.hhs.gov/definitionresearch-misconduct>.

5. COPE Council. COPE retraction guidelines. November 2019 [version 2]. <https://doi.org/10.24318/ cope.2019.1.4>. 
6. Stern AM, Casadevall A, Steen RG, Fang FC. Financial costs and personal consequences of research misconduct resulting in retracted publications. Elife. 2014;3:e02956

7. Steen RG. Retractions in the medical literature: how many patients are put at risk by flawed research? J Med Ethics. 2011;37(11):688-92.

8. Pérez-Escoda A, Jiménez-Narros C, Perlado-Lamo-deEspinosa M, Pedrero-Esteban LM. Social networks' engagement during the COVID-19 pandemic in Spain: health media vs. healthcare professionals. Int J Environ Res Public Health. 2020;17(14):5261.

9. Serrano LR. Coronavirus. Por qué la comunicación tradicional no sirve [Internet]. ANIS; 2021. Available from: http:/ / www.anisalud.com/index.php?option=com_content \&view $=$ article\&id $=5741$

10. Fagbule O. Use of social media to enhance the impact of published papers. Ann Ib Postgrad Med. 2018;16(1):5-6.

11. Xia J, Wu T, Zhou L. Sharing of verified information about COVID-19 on social network sites: a social exchange theory perspective. Int J Environ Res Public Health. 2021;18(3):1-12.

12. Rosenberg H, Syed S, Rezaie S. The Twitter pandemic: the critical role of Twitter in the dissemination of medical information and misinformation during the COVID-19 pandemic. CJEM. 2020;22(4):418-21.

13. Cortegiani A, Catalisano G, Ippolito M, Giarratano A, Absalom AR, Einav S. Retracted papers on SARS-CoV-2 and COVID-19. Br J Anaesth. 2021;126(4):e155-e156.

14.Soltani P, Patini R. Retracted COVID-19 articles: a side-effect of the hot race to publication. Scientometrics. 2020;125(1):819-22.

15. Sutton SW. Altmetrics: what good are they to academic libraries? Kansas Library Association College and University Libraries Section Proceedings. 2014;4(2):article 1.

16. Ioannidis JPA. Coronavirus disease 2019: the harms of exaggerated information and non-evidence-based measures. Eur J Clin Invest. 2020;50(4):e13222.

17. Ortiz-Núñez R. Metric analysis of the scientific production about COVID-19 in scopus. Revista Cubana de Informacion en Ciencias de la Salud. 2020;31(3):1-20.

18. Uysal BB, Islamoglu MS, Koc S, Karadag M, Dokur M. Most notable 100 articles of COVID-19: an Altmetric study based on bibliometric analysis. Ir J Med Sci. 2021:1-7.

19. Parabhoi L. Analysis of the Altmetric top 100 Altmetric Attention Score coronavirus publications. Library Philosophy and Practice. 2021:article 4426.

20. Tornberg HN, Moezinia C, Wei C, Bernstein SA, Wei C, AlBeyati R, Quan T, Diemert DJAssessing the dissemination of COVID-19 articles across social media with Altmetric and PlumX Metrics: correlational study. JJ Med Internet Res. 2021;23(1):e214080.

21. Rao TS, Andrade C. The MMR vaccine and autism: sensation, refutation, retraction, and fraud. Indian J Psychiatry. 2011;53(2):95-96.
22. Wang T, Lund BD. Announcement information provided by United States' public libraries during the 2020 COVID-19 pandemic. Public Library Quarterly. 2020;39(4):283-294.

23. Ladan A, Haruna B, Madu AU. COVID-19 pandemic and social media news in Nigeria: the role of libraries and library associations in information dissemination. International Journal of Innovation and Research in Educational Sciences2020;7(2):125-33.

\section{EC SUPPLEMENTAL FILES}

- Appendix A. Articles included in this study

\section{AUTHORS' AFFILIATIONS}

Amrollah Shamsi, shamsiamrollah@gmail.com, Independent Research, Bushehr, Iran

Brady Daniel Lund, blund2@g.emporia.edu, School of Library and Information Management, Emporia State University, Emporia, KS

Shohreh SeyyedHosseini, tanin64@gmail.com,Knowledge and Information Science, Bushehr University of Medical Sciences, Bushehr, Iran

Received April 2021; accepted June 2021 Articles in this journal are licensed under a Creative Commons Attribution 4.0 International License.

This journal is published by the University Library System of the University of Pittsburgh as part of its D-Scribe Digital Publishing Program and is cosponsored by the University of Pittsburgh Press.

ISSN 1558-9439 (Online) 